\title{
Uma Alternativa Didática para Discussão de Privacidade e Comportamento dos usuários em Redes Sociais: experiência do TECGrupo.Com ${ }^{1}$
}

\author{
Daniel Paiva $^{1}$, Francisco Oliveira ${ }^{2}$ \\ ${ }^{1,2}$ Instituto do Noroeste Fluminense de Educação Superior - Universidade Federal \\ Fluminense (UFF) - 28.470-000 - Santo Antônio de Pádua - RJ - Brazil. \\ profdanielpaiva@gmail.com, francisco25aoliveira@hotmail.com
}

\begin{abstract}
This paper discusses the exposure of personal data in social networks, and the dissemination of inaccurate facts that compromise data privacy. Under an exploratory research methodology, the data raised contribute to an understanding of the aspects of information security, privacy, importance of security policies, and guidelines that should be followed by users on platforms, which are identified under a didactic method configured and applied by future teachers.
\end{abstract}

Resumo. Este trabalho discute exposição de dados pessoais em meio às redes sociais, e a disseminação de fatos imprecisos que comprometem a privacidade de dados. Sob uma metodologia de pesquisa exploratória, os dados levantados contribuem para uma compreensão dos aspectos da segurança da informação, privacidade, importância das políticas de segurança, e diretrizes que devem ser seguidas por usuários nas plataformas, sendo estes, identificados sob um método didático configurado e aplicado por futuros docentes.

\section{Problema de pesquisa}

Este trabalho investigou a exposição de dados pessoais em redes sociais, enquanto potenciais ferramentas de disseminação de fatos imprecisos ao público com implicações acerca da privacidade de dados e o fenômeno de fakenews.

Com a participação de um grupo de licenciandos em Computação, o estudo provocou percepções acerca da importância e da confiabilidade de dados, através de um levantamento sistemático de informações privadas de personalidades, disponíveis online.

\section{Método e forma de Avaliação Aplicada}

Conforme de modelos de pesquisa empregados por Date (2017) e Rodrigues (2017), a metodologia adotada foi a pesquisa exploratória, em um período de dois meses. O estudo consistiu em: (1) pesquisa bibliográfica. (2) Seleção e preparação, onde cada licenciando escolheu uma personalidade midiática ou pessoa pública e realizou (3) busca online de informações a fim de fazer o (4) preenchimento de um formulário sócio

\footnotetext{
${ }^{1} \mathrm{O}$ Trabalho foi publicado na edição do primeiro semestre de 2019 no periódico internacional Brazilian Journal of Technology, Communication, and Cognitive Science. Link: http://www.revista.teccog.net/index.php/revista_tecccog.
} 
econômico fornecido pelo professor responsável. O passo seguinte foi (5) a discussão de diretrizes indicadas para melhor preservação dos dados.

\section{Principais Resultados e Diretrizes de Segurança Digital}

Os dados obtidos indicam falhas graves dos usuários, de terceiros que, porventura tenham acesso a informações e as disponibiliza, e também das plataformas de redes sociais. Neste cenário, o caminho é o maior cuidado com a privacidade através de:

A) Tomada de decisão e informações postas nas redes - cautela e busca de auxílio para melhor escolha de quais informações devem ser deixadas públicas.

B) Busca por instruções para segurança de dados - incentivo à busca de informações detalhadas sobre as políticas de privacidade de cada plataforma.

C) Identificação e combate a distorções com dados privados -maior atenção e busca de meios legais para garantia de confidencialidade dos dados pessoais.

D) Promoção de discussões sobre a privacidade - contribuição como Date (2017), Lobato e Hurel (2018), Rodrigues (2017), Romanini (2018).

\section{Conclusão}

Os resultados da pesquisa complementam o conjunto de conhecimento dos aspectos sociais da Segurança da Informação. Os temas abordados são relevantes em função do atual momento de popularização dos bancos digitais, com ações agressivas de marketing, como por exemplo, o banco BS2 que patrocina um clube de futebol e investe por ano R 15 milhões fixos mais valores variáveis em função de adesão de torcedores.

Os dados contribuem para uma compreensão dos aspectos adjacentes à segurança da informação, à privacidade, à importância das políticas de segurança, e às diretrizes necessárias aos usuários nas plataformas digitais.

A didática relatada é inovadora e está em um ambiente aberto à discussão para que licenciandos, os futuros professores, ampliem o debate no sentido de conscientizar o maior número possível de indivíduos através de intervenções didáticas.

\section{Referências}

DATE, C. J. (2017) The new relational database dictionary: a comprehensive glossary of concepts arising in connection with the relational model of data, with definitions and illustrative examples: [terms, concepts, and examples]. Sebastopol, CA: OReilly.

LOBATO, L. HUREL, L. M. (2018) Os desafios das fake news na América Latina. Disponível em https://www.nexojornal.com.br/ensaio/2018/Os-desafios-das-fakenews-na-Am\%C3\%A9rica-Latina

RODRIGUES, F. DE A. (2017) Coleta de dados em redes sociais: privacidade de dados pessoais no acesso via Application Programming Interface. Tese-Marília, Brasil: Universidade Estadual Paulista.

ROMANINI, Anderson Vinicius. (2018) De elos bem fechados: o pragmatismo e a semiótica peirceana como fundamentos para a tecnologia blockchain utilizada no combate às fake news. São Paulo: Communicare. 